\title{
The temporal dynamics of retention of a context memory: Something is missing
}

\author{
Jerry W. Rudy ${ }^{1}$ and Karli Wright-Hardesty \\ Department of Psychology, Center for Neuroscience, University of Colorado, Boulder, Colorado 80309, USA
}

\begin{abstract}
We use a variation of contextual fear conditioning, called the context pre-exposure facilitation effect (CPFE) to study the rat's memory for context. In this paradigm, the rat is pre-exposed to a conditioning context and later returned to that context, where it is immediately shocked. The memory context is revealed by the fact that pre-exposure to the conditioning context, but not to a different context, greatly enhances conditioned fear produced by immediate shock. We report that rat's retention of the context memory is a nonmonotonic U-shaped function of the interval separating pre-exposure and immediate shock. Retention performance decays rapidly so that within 2 min of pre-exposure there is no evidence that the rat was pre-exposed to the context. Within a few hours, however, a strong CPFE was observed that persisted for at least $28 \mathrm{~d}$. Two hypotheses are discussed: (1) the descending arm of the U represents a retrieval failure, and (2) the U-shaped function represents two discontinuous memory processes initiated in parallel-short-term synaptic changes that are rapidly initiated, but also decay rapidly, and long-term synaptic processes that take time to generate but can endure for days.
\end{abstract}

Conventional thinking about memory begins with the idea that it takes time (hours) for the cellular/molecular events initiated by a target experience to generate the structural changes in synapses that are required for a stable long-term memory (LTM). While the cascade that consolidates the LTM is working to completion, however, behaviors can be observed that clearly reflect memory for the target experience. Thus, memory theorists since William James have entertained the idea that a second memory process called short-term memory (STM), which contains elements that can be rapidly assembled into a memory trace, maintains a record of the experience. This trace can support retrieval and influence behavior but decays rapidly.

Contemporary support for this multiple trace view has come from a variety of experiments (see Emptage and Carew 1993; Rosenzweig et al. 1993; Crow et al. 1997; Izquierdo et al. 2002; Sutton et al. 2002). A paradigmatic illustration is provided by several recent experiments in which the protein synthesis inhibitor anisomycin is administered prior to or immediately after a target experience and the animal is tested at various intervals following training. Experiments of this type (Bourtchouladze et al. 1998; Schafe et al. 1999) have revealed that anisomycin impairs performance at long retention intervals (e.g., $24 \mathrm{~h}$ ) but has no effect on performance at shorter intervals (e.g., 1-3 h). This pattern of results has been interpreted to mean that behavior can be supported by an STM process that does not require protein synthesis and by an LTM that does. It has also been suggested that there may be several memory processes with different decay properties that support retrieval (see Rosenzweig et al. 1993; Izquierdo et al. 2002; Sutton et al. 2002).

Regardless of whether one or more processes support retrieval, performance usually decreases monotonically as the retention interval decreases. Assuming there are multiple storage processes, this monotonic function suggests that their decay properties are seamlessly interfaced such that before information has decayed from one process, another process has come on line to support retrieval of the target experience. So, under normal

\footnotetext{
${ }^{1}$ Corresponding author.

E-mail JRudy@Clipr.Colorado.Edu; fax (303) 492-2967.

Article published online ahead of print. Article and publication date are at http://www.learnmem.org/cgi/doi/10.1101//m.84005.
}

conditions one would have little reason to suspect that there are multiple storage processes contributing to the behavior. Thus, the concept of multiple memory storage processes with different decay functions has emerged primarily from experiments in which the brain has been altered prior to or after the target experience.

Although the typical retention function is monotonic, even in the intact organism there have been occasional reports of "gaps" in this function so that the function is nonmonotonic (see Kamin 1963; Irwin et al. 1968; Zerbolio 1969; Cherkin 1971; Messenger 1971; Sanders and Barlow 1971; Riege and Cherkin 1972; Rudy and Morledge 1994; Ploner et al. 1998). Such gaps in the retention function have been interpreted as a discontinuity between independent memory processes-information held in one storage process has decayed before the next trace has matured to the point that it can support the behavior (Cherkin 1971). However, they have also been interpreted as (1) reflection of the properties of a single memory trace that is modulated by other variables (Gold and McGaugh 1975), (2) the result of emotional behavior interfering with performance shortly after training (Squire 1975), and (3) a retrieval failure (Spear 1971).

One reason that these experiments have permitted so many alternative interpretations is that, with the exception of the Ploner et al. (1998) study with people, electric shock was part of the experience that established the memory. So, in our experiments the target memory-producing experience did not contain shock, food reinforcement, or any explicit contingency between the animal's behavior and some other event. We studied the rat's formation of a memory for context. This occurs when it explores a novel context. By studying this type of memory, if a nonmonotonic retention function is found, we could discount the interpretations mentioned above.

We used the context pre-exposure facilitation effect (CPFE) to study the retention of the context memory. The CPFE derives from an important observation Fanselow (1990) made when he analyzed the failure of immediate shock to produce contextual fear conditioning. If a rat is placed into a context and shocked immediately, later it will display almost no fear of that context. However, if it is pre-exposed to the context the day before, immediate shock will produce substantial freezing (Fanselow 1990; 


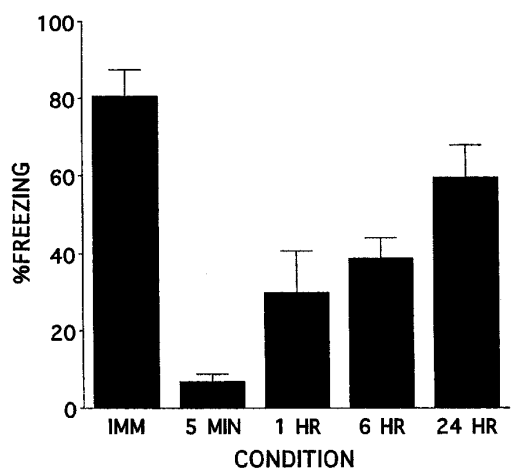

Figure 1. The results of experiment 1 . Mean percentage of freezing in the test $24 \mathrm{~h}$ following immediate shock as a function of the retention interval separating context pre-exposure and immediate shock. Bars, SE.

Westbrook et al. 1994; Rudy and O'Reilly 2001). According to Fanselow (1990) the reason immediate shock fails to support conditioning is that the rat did not have sufficient time to encode a representation of the context prior to immediate shock. Thus, pre-exposure facilitates the amount of conditioning produced by immediate shock because it allows the rat to establish a memory of the context before the immediate shock. This memory is then retrieved prior to the immediate shock by a subset of features that make up the context (Fanselow 1990) or by cues associated with transporting the rat to the conditioning chamber (Rudy and O'Reilly 2001). It is this retrieved memory representation of the context that is associated with the immediate shock (see Rudy and O'Reilly 2001; Rudy et al. 2002).

We also have conducted a number of studies that are consistent with the hypothesis that the acquisition, consolidation, and retrieval of the memory for the pre-exposed context involve the formation of a conjunctive representation that depends on the hippocampus (see Rudy et al. 2004). Specifically, the CPFE is significantly reduced by (1) anterograde damage to the dorsal hippocampus (DH) (Rudy et al. 2002); (2) post-context exposure injection of the protein synthesis inhibitor anisomycin into the DH (Barrientos et al. 2002); (3) inactivation of the DH by the GABA agonist muscimol prior to context exposure, prior to immediate shock, or prior to testing (Matus-Amat et al. 2004); and (4) inactivation of the ventral hippocampus $(\mathrm{VH})$ prior to context exposure or by injection of anisomycin into the $\mathrm{VH}$ following context pre-exposure (Rudy and Matus-Amat 2005). Moreover, in a previous study (Rudy and Morledge 1994) on the ontogeny of contextual fear conditioning, we reported data suggesting that the function relating performance to the retention of a context memory may be nonmonotonic. Thus, we used the CPFE paradigm to test the hypothesis that a nonmonotonic retention performance curve could be obtained for an experience that did not contain shock.

\section{Results}

\section{Experiment 1: Retention of the context memory} is a nonmonotonic function of the retention interval The standard CPFE experiment consists of three phases: (1) preexposure to the context, (2) immediate shock, and (3) test for conditioned freezing. The retention interval separating preexposure and immediate shock is generally $\sim 24 \mathrm{~h}$. As noted, preexposure separated from immediate shock by $24 \mathrm{~h}$ significantly increases the amount of conditioning normally produced by immediate shock. However, no one has systematically investigated the effect of varying the retention interval-the interval between pre-exposure and immediate shock-on the CPFE. Thus, in experi- ment 1 , all rats received a series of six context exposures, but the retention interval separating pre-exposure and immediate shock varied. This pre-exposure procedure was used initially because we had used it with success in a number of recent experiments (see Rudy et al. 2002; Matus-Amat et al. 2004). Rats in the immediate (IMM) condition were shocked without removing them from the context. For others, the retention interval was either $5 \mathrm{~min}, 60$ $\min , 6 \mathrm{~h}$, or $24 \mathrm{~h}$. Following the last pre-exposure, the rats in these conditions were returned to their home cage before being transported back to the context for immediate shock. Finally, rats in each condition were tested $24 \mathrm{~h}$ after the immediate shock session.

Figure 1 shows that performance was dramatically influenced by the retention interval. As expected, rats in the IMM condition and rats in the 24-h retention interval condition displayed strong fear to the context. Strong freezing by rats in the IMM condition is not surprising because they did not have to retain a memory for the context. This training is a form of delayed contextual fear conditioning. Note however, that when the interval between pre-exposure and shock was only $5 \mathrm{~min}$, rats displayed almost no freezing, but as this interval increased so did the amount of freezing. An analysis of variance indicated that there were significant differences among the groups $\left(F_{(4,32)}=13.3, P<0.001\right)$. Post hoc comparisons $(P<0.05)$ indicated that (1) rats in the 5 -min condition froze less than did rats in all other conditions, (2) rats in the 1-h condition froze less than did those in the IMM and 24-h condition, and (3) rats in the 6 -h condition froze less than did those in the IMM condition.

\section{Experiment 2: Memory for context rapidly becomes inaccessible}

The previous experiment revealed that the memory for context either is not available or cannot be accessed within 5 min after the last exposure but that the memory returns to a usable state over a several-hour period. In experiment 2 , we compressed the retention interval to better determine how quickly the memory becomes unavailable. The interval separating pre-exposure and immediate shock was either $5 \mathrm{sec}, 30 \mathrm{sec}, 2 \mathrm{~min}$, or $24 \mathrm{~h}$. As shown in Figure 2, rats in the 5-sec and 24-h retention interval conditions display similarly high levels of freezing, but retention performance dropped rapidly so that at the 2-min interval rats displayed almost no freezing. An analysis of variance revealed differences among the groups $\left(F_{(3,27)}=6.45, P<0.002\right)$. Post hoc tests indicated that the 2-min condition differed from all other conditions $(P<0.05)$.

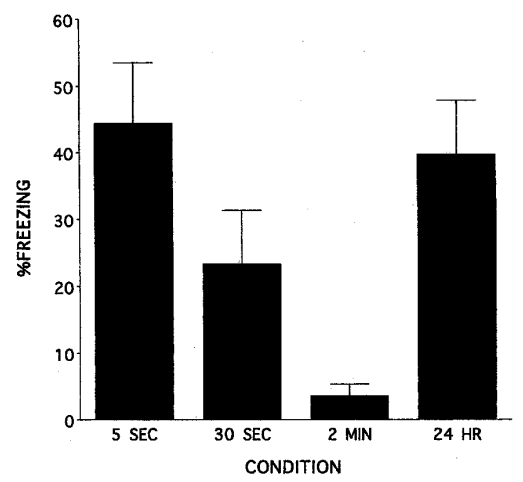

Figure 2. The results of experiment 2. Mean percentage of freezing in the test $24 \mathrm{~h}$ following immediate shock as a function of the retention interval separating context pre-exposure and immediate shock in experiment 2. Bars, SE. 


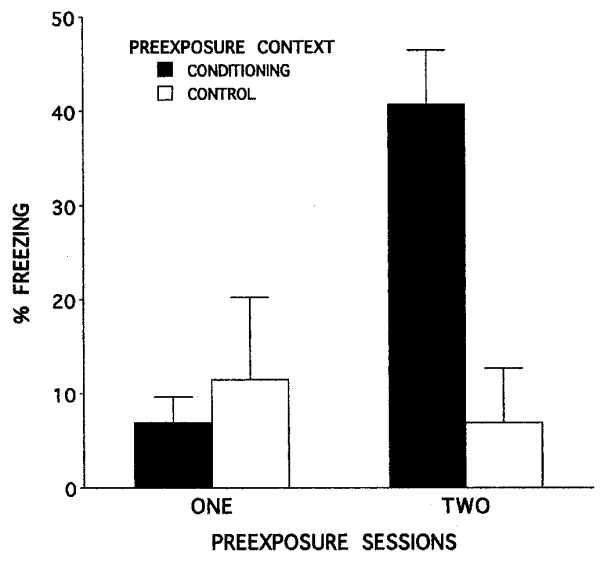

Figure 3. The results of experiment 3. Mean percentage of freezing in the test $24 \mathrm{~h}$ following immediate shock as a function of the number of pre-exposure sessions. Bars, SE. A 5-min retention interval separated the last pre-exposure and immediate shock.

\section{Experiments 3 and 4: Does repeated exposure make the memory trace temporarily inaccessible?}

The first two experiments revealed that retention of a context memory is a $U$-shaped function of the retention interval. Retention falls dramatically over the course of $2 \mathrm{~min}$ and is still absent at $5 \mathrm{~min}$, but then it gradually improves over several hours until $24 \mathrm{~h}$ when it has recovered to the level exhibited a few seconds after the immediate shock. Here we consider two interpretations of this function. The first is that the descending arm of the Ushaped function is mediated by a memory storage process that has a rapid decay property and that the ascending arm of the $U$ reflects the operations of consolidation processes that bind together the elements of the context experience into a stable memory trace that can later be retrieved. By this account, the flat period of the U-shape function reflects a discontinuity in at least two underlying memory processes, one that supports rapid acquisition but has a rapid decay function, and another that develops slowly but has a relatively slow decay function. A second interpretation of the U-shaped function observed in experiments 1 and 2 is that an established memory trace is continuously available throughout the retention period, but variables embedded in the procedures render it inaccessible for some period of time (Spear 1971) by creating some kind of "neural noise." For example, the procedure used to establish the context memory entailed a series of six pre-exposures. It is possible that multiple pre-exposures per se render the memory trace inaccessible for some period of time following the last pre-exposure. We conducted two experiments to evaluate this hypothesis.

In experiment 3, we compared rats that received a single session of multiple exposures to the context with rats that had two identical sessions of multiple pre-exposures separated by 24 h. All rats received immediate shock $5 \mathrm{~min}$ after the last preexposure. An important feature of this experiment was that it also included rats that received an identical pattern of preexposure but were exposed to a totally different context, a mouse cage. The inclusion of this control condition allows us to determine if rats pre-exposed to the conditioning context showed any benefit of exposure to the conditioning context when the retention interval was $5 \mathrm{~min}$.

As shown in Figure 3, the rats that received a single session of six pre-exposures to the context displayed very little freezing. They did not differ from the single-session control rats exposed to a different context. In contrast rats that received two sessions of repeated exposure to the context displayed much more freez- ing than did their controls that were exposed to a different context. A two-factor analysis of variance revealed a significant interaction between the number of pre-exposure sessions (two versus one) and the type of exposure (conditioning context versus control context; $F_{(1,16)}=7.88, P<0.01$. Post hoc analyses indicated that rats exposed twice to the conditioning context differed from all groups $(P<0.05)$. No other groups differed.

The results of this experiment allow several conclusions. First, multiple pre-exposures $5 \mathrm{~min}$ prior to immediate shock per se do not produce the flat part of the $U$. This is because rats given two sessions of repeated exposure to the context displayed strong contextual fear. Second, the performance of the rats in the singlesession pre-exposure group replicates the results reported in the first two experiments and indicates there was no detectable benefit of exposure to the conditioning context when the retention interval is $5 \mathrm{~min}$ because they did not differ from rats exposed to a totally different context. Third, however, these results do not rule out the consolidation hypothesis because it would predict that given a 24 -h interval between pre-exposure and immediate shock, the memory trace should become consolidated and accessible even if multiple exposures to the context preceded immediate shock. This is what was observed in the two-session exposure condition.

In experiment 4 , we used a different approach to evaluate the role of multiple exposures. Rats were given only one 5-min exposure to the conditioning context. This was followed by immediate shock $5 \mathrm{~min}$ or $24 \mathrm{~h}$ later. In this experiment shock was not strictly immediate. The rats were in the conditioning chamber for 4 sec before shock was delivered. We increased the time before shock in order to increase the opportunity for the memory of the pre-exposed context to be retrieved, if indeed it was available. As shown in Figure 4, rats in the 24-h retention condition displayed significantly more freezing than did rats in the 5-min condition $\left(F_{(1,22)}=7.03, P<0.01\right)$. Thus, even without multiple pre-exposures, conditioned freezing is markedly depressed at the 5-min retention interval. So multiple pre-exposures are not necessary to produce the effect. Moreover, we failed to find evidence of a retrieved context memory at the 5-min interval even when the rats were given $4 \mathrm{sec}$ to retrieve this memory before the shock.

This experiment also makes another point. Fanselow (1990) argued that in order for context exposure to facilitate conditioning produced by shock, (1) the rat has to acquire the representation of the context, and (2) this representation has to be retrieved prior to the shock. Retrieval of the context memory can be achieved either by some subset of the cues of the context (Fanselow 1990) or by the transport cues while bringing the rat to the context (see Rudy and O'Reilly 2001; Rudy et al. 2002).

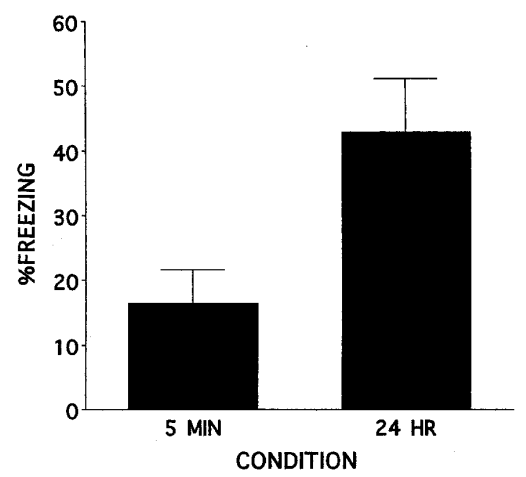

Figure 4. The results of experiment 4. Mean percentage of freezing in the test $24 \mathrm{~h}$ following shock as a function of the retention interval separating context pre-exposure and shock. Bars, SE. 
In the true immediate shock procedure employed in experiments 1 through 3, the context memory must be retrieved by transport cues because the rat has no time to sample the context. So, one might argue that the flat function of the $U$ was due to the inability of the transport cues to retrieve the context memory at the 5 -min retention interval. In experiment 4 , retrieval of the context memory did not depend on transport cues because the rat was placed into the context for 4 sec prior to shock, allowing for some subset of the features of the context to retrieve the entire context memory. This experience was sufficient to produce substantial conditioning when the retention interval was $24 \mathrm{~h}$ but not when it was only $5 \mathrm{~min}$. This outcome makes it unlikely that the flat part of the $U$ is a product of the nature of the retrieval experience.

\section{Experiment 5: The memory for context is enduring}

The experiments to this point have focused on the rapid decline in conditioned freezing that is produced by immediate shock when the retention interval increases from $5 \mathrm{sec}$ to $2-5 \mathrm{~min}$. We have also examined the effects of context pre-exposure with retention intervals of 7 and $28 \mathrm{~d}$. In each case we compared the effects of exposure to the conditioning context with exposure to a novel but different context, a mouse cage. We used the same series of six exposures and immediate shock employed in experiments 1 through 3 . The rats were tested $24 \mathrm{~h}$ after immediate shock. As shown in Figure 5, rats exposed to the conditioning context display robust freezing at both the 7-d and 28-d interval. Rats exposed to the mouse cage displayed almost no freezing. At both retention intervals, the difference between rats exposed to the context and those exposed to the mouse cage was significant: (1) $F_{(1,7)}=68.7, P<0.001$ for the 7 -d retention test, and (2) $F_{(1,10)}=49.4, P<0.001$, for the 28-d retention test. Although comparing across experiments can be misleading, it is interesting to note that the levels for freezing obtained in these experiments were the highest we have observed, suggesting that the memory for context either continues to strengthen or, at the very least, shows no sign of weakening.

\section{Discussion}

The empirical findings are clear. Conditioned freezing produced by immediate shock is a nonmonotonic U-shaped function of the retention interval separating the rat's exposure to the context and immediate shock. When that interval is brief, $5 \mathrm{sec}$, freezing is robust, but it rapidly declines so that when the interval is $2-5$

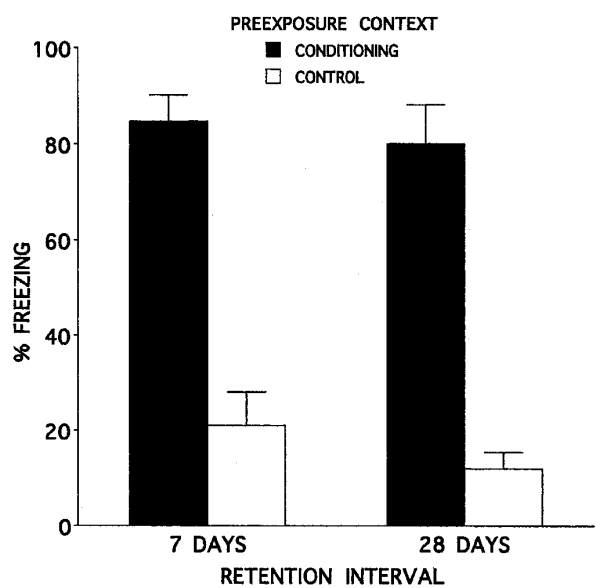

Figure 5. The results of experiment 5 . Mean percentage of freezing in the test $24 \mathrm{~h}$ following immediate shock as a function retention interval separating pre-exposure and immediate shock. Bars, SE. min there is almost no freezing. This absence of freezing at this short interval is not a product of a particular pre-exposure procedure. It occurred when a series of pre-exposures preceded shock and when only a single exposure was given. It also did not depend on a particular shock procedure; it occurred if shock was immediate or if it were delayed for $4 \mathrm{sec}$. Retention performance, however, improved as the retention interval increased from $1 \mathrm{~h}$ to 6-24 h. Robust freezing was still observed even at retention intervals of 7 and $28 \mathrm{~d}$.

As noted, early interpretations of such nonmonotonic retention functions assumed that they reflect the discontinuity between independent memory processes-information held in one storage process has decayed before the next trace has matured to the point that it supports the behavior (Cherkin 1971). In building the case for a dual trace theory, however, Squire (1975) was quite cautious about this isomorphic mapping of the retention function onto the separated memory processes. His primary concern was that the training experiences used in the existing literature contained an emotional event, shock, which could alter the arousal level and behavioral activity of the animal at the time of testing in a way that would interfere with test performance. By extension, this emotional state could also create an internal environment that might interfere with retrieval of the memory (Spear 1971). Thus, by these accounts the flat part of the Ushaped function does not reflect discontinuity between the decay of one memory process and maturation of a second process.

The target context memory in our experiments, however, was established as a product of the rat exploring a novel environment. The experience did not contain shock. So, to some extent these results should reduce the worry that the flat part of the $U$ is simply a performance artifact. Nevertheless, although we produced no evidence to support the performance/retrieval interpretation (see experiment 3), our experiments do not completely rule out this possibility.

However, Rudy and Morledge (1994) reported a series of experiments that did rule out this possibility. They looked at the retention of conditioned fear in rats $23-35 \mathrm{~d}$ old. In these experiments rats were placed into the conditioning context for 2 min and then shocked. They were tested either immediately, $10 \mathrm{~min}$, or 1,3 , or $24 \mathrm{~h}$ later. The test revealed that performance (freezing) was also a nonmonotonic U-shaped function of the retention interval. Strong freezing was seen at the immediate and 24-h intervals but not at the 10-min or 1- or 3-h intervals. They hypothesized that the increasing portion of the U-shaped function reflects the time it took the rat to consolidate the representation required to retrieve the memory of the shocked context. The implication of this hypothesis was that if rats had already consolidated the context representation because of pre-exposure, it would be available for activation at these intermediate tests, and consequently, such rats should not display a freezing deficit when tested at these retention intervals. In fact, Rudy and Morledge found that rats pre-exposed to the context displayed much more conditioned fear than rats not pre-exposed to the context when the retention interval separating shock and testing was only 10 min. If the failure of the rats to display fear to the context was simply due to either (1) an emotional state produced by shock that either masked or prevented the retrieval of fear memory or (2) post-shock behavioral effects that interfered with testing, then context pre-exposure should not have rescued performance. Thus, Rudy and Morledge (1994) concluded that the U-shaped function seen in the retention of contextual fear conditioning was the product of a discontinuity between a rapidly decaying short-term process and the time it takes to construct an LTM representation of the context that is then available for retrieval.

If one accepts Rudy and Morledge's conclusion that reduced freezing was not due to the rat's emotional response to shock 
masking retrieval of the context fear memory at the 10-min retention interval, then there is no reason to believe that the emotional state produced by simply exploring a novel context should mask retrieval of the context memory during the flat portion of our U curve. If so, then we would argue that the best interpretation of our data is that they are a product of a discontinuity between at least two different processes that can support memory: (1) synaptic processes that are modified quickly but have a rapid decay function and (2) synaptic changes that require time but have a much slower decay function.

We assume that the freezing behavior observed in the ascending arm of the U-shaped function (when the retention interval was long) depended on a slow developing consolidated memory trace. It supports the retrieval of a context memory at the time of immediate shock that can be associated with the shock. In contrast, freezing observed when the retention interval was short ( $<2 \mathrm{~min}$ ) was supported by conditioning to a memory trace established by the pre-exposure experience per se and not to a memory retrieved at the time of immediate shock. By this account, the descending arm of the U-shaped function reflects the decay of this trace.

We know that the rat's memory for context at the 24-h retention interval can be blocked by the protein synthesis inhibitor anisomycin injected into either $\mathrm{DH}$ or $\mathrm{VH}$ following preexposure (Barrientos et al. 2002; Biedenkapp and Rudy 2004; Rudy et al. 2004). Such a result is usually interpreted to mean that LTM depends on the synthesis of new proteins. It is possible that the increasing arm of the $U$ function reflects the time it takes for the initial protein synthesis-dependent consolidation of the context memory; however, it might also be the case that the initial increase is not protein synthesis dependent. This intermediate level of performance might reflect some other modification of synapses that does not depend on protein synthesis. This will have to be determined by additional experimentation.

Our account is a version of a multiple-trace theory. Such accounts raise the question as to whether the target experience initiates a set of processes that are serially dependent or executed in parallel (Squire 1975; Izquierdo et al. 2002). A serial arrangement implies that a subsequent process depends on, or is initiated by, the preceding process. The parallel process view argues that there is no dependency and that the various means by which the nervous system can store information are initiated simultaneously by the target input.

Our experiments cannot discriminate these two views. However, a critical implication of the parallel view is that there are manipulations that can impair any putative process, whether it occurs early or late in relationship to the target experience, while leaving unaffected any other. Izquierdo and colleagues (1998, 2002) have presented a massive amount of evidence that is consistent with the parallel view of rodent memory processing, and Emptage and Carew (1993) have presented evidence that this is also the case in Aplysia neurons mediating synaptic facilitation. So, based on the existing literature, one would suspect that the processes mediating memory for context are initiated in parallel.

In conclusion, conditioned freezing produced by immediate shock is a nonmonotonic U-shaped function of the retention interval separating context exposure and shock. Thus, nonmonotonic retention functions can be observed following training events that do not contain shock. Although we cannot definitively rule out the possibility that the flat part of the $U$ function is a performance impairment or a retrieval deficit, when our results are considered together with those reported by Rudy and Morledge (1994), a good case can be made that this $U$ function is a product of a discontinuity between at least two different processes that can support memory. Additional experiments will be needed to determine if we are correct.

\section{Materials and Methods}

\section{Subjects}

Subjects were adult (73-85 d, 300-375 g) male Long Evans rats born to animals obtained from Charles Rivers Breeders and bred at the University of Colorado. Animals were housed two to four per cage, maintained on a 12-h light/12-h dark cycle (lights on at 6:00 a.m.) at $25^{\circ} \mathrm{C}$, and allowed free access to food and water. Experiments were conducted in accordance with protocols approved by the University of Colorado Animal Care and Use Committee.

\section{Apparatus}

The conditioning context consisted of an Igloo ice chest (54 $\mathrm{L} \times 30 \mathrm{~W} \times 27 \mathrm{H} \mathrm{cm}$ ) with a white interior. A speaker and an activated 6-W clear light bulb were mounted on the ceiling. The ice chest door remained open across the duration of the experiment. The chest was located in a room that was illuminated by two 60 -W light bulbs. The conditioning chamber $(26 \times 21 \times 24$ $\mathrm{cm}$, length $\times$ width $\times$ height) was located inside the chest and consisted of clear plastic sides and window screen tops. The 2-sec, $1.5-\mathrm{mA}$ shock was delivered through a removable floor of stainless steel rods (Coulbourn Model E63-23-MOD001). Each rod was $0.5 \mathrm{~cm}$ in diameter, spaced $1.75 \mathrm{~cm}$ center to center, and was wired to a shock generator and scrambler (Coulbourn Model H13-16). The chamber was cleaned with water before each animal was placed inside.

\section{Behavioral procedures}

\section{Context pre-exposure}

Rats were transported in pairs to the conditioning chamber in a light-sealed black bucket. Subjects were allowed to freely explore the context for $5 \mathrm{~min}$ and were then transported back to their home cage where they remained for $20 \mathrm{sec}$. The pair was again transported in the above manner and placed in the conditioning chambers for $40 \mathrm{sec}$. This procedure was repeated five times. In total, each animal received an initial context exposure of $5 \mathrm{~min}$ followed by five 40 -sec exposures. In experiment 4 there were no 40-sec exposures.

For experiment 3, some of the rats received two preexposure sessions separated by $24 \mathrm{~h}$, and some received the standard single pre-exposure. Within these two groups, some rats were exposed to the conditioning chamber (single, $n=4$; double, $n=6$ ), and the remainder were pre-exposed in an alternate "control" context consisting of a small, opaque mouse cage $(26 \times 16 \times 12 \mathrm{~cm}$, length $\times$ width $\times$ height $)$ located in a different room adjacent to that where conditioning occurred (single, $\mathrm{n}=6$; double, $\mathrm{n}=6$ ). At the end of pre-exposure, rats were returned to their home cage until the time of immediate shock. Throughout the experiment, the lid to the bucket was on during transport to the chamber but removed during return to the home cage.

\section{Immediate shock}

In experiment 1 , the interval between pre-exposure and immediate shock was either $5 \mathrm{~min}(\mathrm{n}=7), 1 \mathrm{~h}(\mathrm{n}=8), 6 \mathrm{~h}(\mathrm{n}=8), 24 \mathrm{~h}$ $(n=7)$, or immediately following the last 40 -sec exposure before return to the home cage $(n=7)$. The intervals were $5 \mathrm{sec}$ (animals were removed from the chamber, placed in the transport bucket for $5 \mathrm{sec}$, and returned for shock; $\mathrm{n}=8), 30 \mathrm{sec}(\mathrm{n}=8), 2 \mathrm{~min}$ $(\mathrm{n}=8)$, or $24 \mathrm{~h}(\mathrm{n}=7)$ in experiment 2 and $5 \mathrm{~min}$ in experiment 3 . In experiment 4 , shock occurred either $5 \min (n=12)$ or $24 \mathrm{~h}$ $(\mathrm{n}=12)$ following pre-exposure, and for experiment 5 the interval was either $7 \mathrm{~d}$ or $28 \mathrm{~d}$. Subjects in experiment 5 were exposed either in the conditioning chamber $(7 \mathrm{~d}, \mathrm{n}=4 ; 28 \mathrm{~d}, \mathrm{n}=6)$, or in the alternate context ( $7 \mathrm{~d}, \mathrm{n}=5 ; 28 \mathrm{~d}, \mathrm{n}=6$ ) as described above. All rats were returned to the home cage following pre-exposure except when the pre-exposure-shock interval was $5 \mathrm{sec}$.

At the time of immediate shock, each rat was transported to the conditioning room in the black bucket with the lid on, placed 
in the context, immediately exposed to a 2 -sec, $1.5 \mathrm{~mA}$ shock, and quickly removed and returned to its home cage. This procedure was used for all experiments except experiment 4, where the rats were placed in the chamber for $4 \mathrm{sec}$ before shock was administered.

\section{Testing}

Twenty-four hours following immediate shock, subjects were placed in the conditioning chamber, and contextual fear was assessed for $6 \mathrm{~min}$. In all experiments, freezing, the rat's natural response to anticipated danger (Blanchard et al. 1976), was the measure of conditioned fear and indicated by the absence of all movement excluding breathing. By using a sampling procedure, each rat was judged as either freezing or active every 10th second. The two behavioral observers had no knowledge of the subject's treatment condition, and inter-rater reliability was no $<0.97$ for all experiments. Pre-exposure, conditioning, and testing occurred between 7:00 a.m. and 11:30 a.m. in all experiments except experiment 1 , where rats in the 6 -h group were shocked and tested between 2:00 p.m. and 5:00 p.m.

\section{Acknowledgments}

This research was supported by National Institutes of Health grant MH 61316-05. The publication costs of this article were defrayed in part by payment of page charges. This article must therefore be hereby marked "advertisement" in accordance with 18 USC section 1734 solely to indicate this fact.

\section{References}

Barrientos, R.M., O’Reilly, R.C., and Rudy, J.W. 2002. Memory for context is impaired by injecting anisomycin into dorsal hippocampus following context exploration. Behav. Brain Res. 134: 291-298.

Biedenkapp, J.C. and Rudy, J.W. 2004. Context memories and reactivation: Constraints on the reconsolidation hypothesis. Behav. Neurosci. 118: 956-964.

Blanchard, R.J., Fukunaga, K.K., and Blanchard, D.C. 1976. Environmental control of defensive reactions to footshock. Bull. Psychonomic Soc. 8: 129-130.

Bourtchouladze, R., Abel, T., Berman, N., Gordon, R., Lapidus, K., and Kandel, E.R. 1998. Different training procedures recruit either one of two critical periods for contextual memory consolidation, each of which requires protein synthesis and PKA. Learn. Mem. 5: 365-374.

Cherkin, A. 1971. Biphasic time course of performance after one-trial avoidance training in the chick. Comm. Behav. Biol. 5: 379-383.

Crow, T., Siddiqui, V., and Dash, P.K. 1997. Long-term enhancement but not short-term in Hermissenda is dependent on mRNA synthesis. Neurobiol. Learn. Memory. 68: 340-347.

Emptage, N.J. and Carew, T.J. 1993. Longterm synaptic facilitation in the absence of short term facilitation in aplysia neurons. Science 262: 253-256.

Fanselow, M.S. 1990. Factors governing one trial contextual conditioning. Anim. Learn. Behav. 18: 264-270.

Gold, P. and McGaugh, J.L. 1975. A single trace, two process view of memory. In Short-term memory (eds. D. Deutsch and J.A. Deutsch), pp. 356-379. Academic Press, New York.

Irwin, S., Banuazizi, A., Kalser, S., and Curtis, A. 1968. One trial learning in the mouse. I. Its characteristics and modification by experimental-seasonal variables. Psychopharmacologia 12: 286-302.

Izquierdo, I., Barros, D.M., e Souza, T.M., Izquierdo, L.A., and Medina, J.H. 1998. Mechanisms for different types of memory differ. Nature 393: $35-36$.

Izquierdo, L.A., Barros, D.M., Vianna, M.R.M., Coitinho, A., e Silva T.D., Choic, H., Moletta, B., Medina, J.H., and Izquierdo, I. 2002. Molecular pharmacological dissection of short-term and long-term memory. Cell. Mol. Neurobiol. 22: 269-287.

Kamin, L. 1963. Retention of an incompletely learned avoidance response. J. Comp. Physiol. Psychol. 56: 713-718.

Matus-Amat, P., Higgins, E.A., Barrientos, R.M., and Rudy, J.W. 2004. The role of the dorsal hippocampus in the acquisition and retrieval of context memory representations. J. Neurosci. 24: 2431-2439.

Messenger, J.B. 1971. Two stage recovery of a response in Sepia. Nature 232: 203-204.

Ploner, C.J., Gaymard, B., Rivaud, S., Agid, Y., and Pierrot-Deseilligny, C. 1998. Temporal limits of spatial working memory in humans. Eur. J. Neurosci. 10: 794-797.

Riege, W.H. and Cherkin, A. 1972. One-trial learning in goldfish: Temperature dependence. Behav. Biol. 7: 255-263.

Rosenzweig, M.R., Bennett, E.L., Colombo, P.J., Lee, D.W., and Serrano, P.A. 1993. Short-term, intermediate-term and long-term memories. Behav. Brain Res. 57: 193-198.

Rudy, J.W. and Matus-Amat, P. 2005. Ventral hippocampus supports a memory representation of context and contextual fear conditioning: Implications for a unitary function of the hippocampus. Behav. Neurosci. (in press).

Rudy, J.W. and Morledge, P. 1994. The ontogeny of contextural fear conditioning: Implications for consolidation, infantile amnesia, and hippocampal system function. Behav. Neurosci. 108: 227-234.

Rudy, J.W., and O'Reilly, R.C. 2001. Conjunctive representations, the hippocampus, and contextual fear conditioning. Cogn. Affect. Behav. Neurosci. 1: 66-82.

Rudy, J.W., Barrientos, R.M., and O'Reilly, R.C. 2002. The hippocampal formation supports conditioning to memory of a context. Behav. Neurosci. 116: 530-538.

Rudy, J.W., Huff, N., and Matus-Amat, P. 2004. Understanding contextual fear conditioning: Insights from a two process model. Neurosci. Biobehav. Rev. 28: 675-685.

Sanders, G.D. and Barlow, J.J. 1971. Variations in retention performance during long-term memory formation. Nature 232: 203-204.

Schafe, G.E., Nadel, N.V., Sullivan, G.M., Harris, A., and LeDoux, J.E. 1999. Memory consolidation for contextual and auditory cue fear is dependent on protein synthesis, PKA, and MAP kinase activity. Learn. Mem. 6: 97-110.

Spear, N.E. 1971. In Animal memory. Academic Press, New York.

Squire, L.R. 1975. Short-term memory as a biological entity. In Short-term memory (eds. D. Deutsch and J.A. Deutsch), pp. 2-42. Academic Press, New York.

Sutton, M.A., Ide, J., Masters, S.E. and Carew, T.J. 2002. Interaction between amount and pattern of training in the induction of intermediate and long-term memory in Aplysia. Learn. Mem. 9: 29-40.

Westbrook, R.F., Good, A.J., and Kiernan, M.J. 1994. Effects of the interval between exposure to a novel environment and the occurrence of shock on the freezing response of rats. Q. J. Exp. Psychol. 47B: 427-436.

Zerbolio, D.J. 1969. Memory storage: The first post-trial hour. Psychonomic Sci. 1: 57-58.

Received July 20, 2005; accepted in revised form January 4, 2005. 


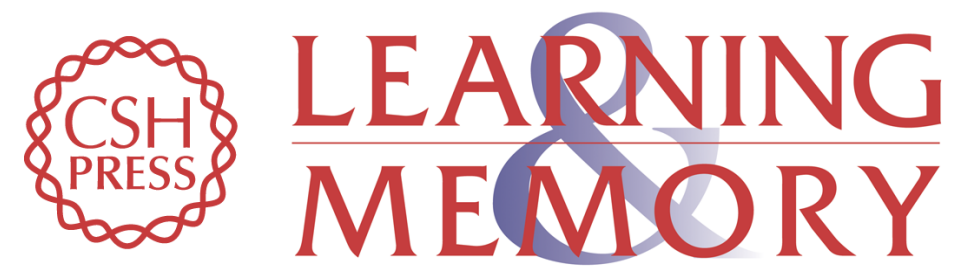

\section{The temporal dynamics of retention of a context memory: Something is missing}

Jerry W. Rudy and Karli Wright-Hardesty

Learn. Mem. 2005, 12:

Access the most recent version at doi:10.1101/lm.84005

References This article cites 23 articles, 5 of which can be accessed free at:

http://learnmem.cshlp.org/content/12/2/172.full.html\#ref-list-1

License

Email Alerting Receive free email alerts when new articles cite this article - sign up in the box at the Service top right corner of the article or click here. 